\title{
Consumers Perception on Prepaid Cards: Survey and Analysis
}

\author{
Mohammad Adib Khairuddin, Mohd Afizi Mohd Shukran \\ Kamaruzaman Maskat, Mohd Rizal Mohd Isa \\ Faculty of Science and Technology Defense, Department of Computer Science, \\ National University Defense University of Malaysia \\ Sungai Besi Camp 57000, Kuala Lumpur, Malaysia \\ E-mail: \{adib, afizi, kamaruzaman, rizal\}@upnm.edu.my
}

Received: October 26, 2011

Accepted: November 28, $2011 \quad$ Published: January 1, 2012

doi:10.5539/mas.v6n1p131

URL: http://dx.doi.org/10.5539/mas.v6n1p131

\begin{abstract}
The prepaid card market is growing rapidly. Its features have attracted many consumers. As a result, consumers require high quality services from prepaid cards companies. Moreover, high demand in surveys and feedbacks are required so that high quality of prepaid card services can be achieved in order to manipulate consumer perceptions. Therefore, this paper will present the surveys and analysis on consumer perception on prepaid cards which aim to become an important reference both for industry as it adopts better high quality prepaid card services.
\end{abstract}

Keywords: Prepaid cards, Consumer perceptions, Customer services

\section{Introduction}

The current economic crisis that swept across almost all countries worldwide, leads to an alarming increase of debt and unemployment with no indication of subsiding. Reuters (Mutikani L., 2009) reported that the US unemployment rate soared to $8.9 \%$ in April 2009 as a result of 5.7 million people losing their jobs, the highest since 1983. Likewise, the unemployment rate suffered by European region for February 2009 alone reported (Eurostat, 2009) to be at 7.9\% with 19.156 million jobless. Specifically, in the UK (U. K. O. f. N. Statistics, 2009), the unemployment rate reported for the first 3 months of 2009 is at $7.1 \%$, with 2.22 million number of people out of work. Interestingly, the unemployment rate for the month of March 2009 faced by Australia (Greber J., 2009) is at $5.7 \%$, a trivial amount compare to the other recorded readings, but the ripples are real and depressing, with the number of people employed dropped 34,700 from February 2009.

Based from the above published figures, we can further assume that the demand for this unemployed and retrenched group to have the necessary purchasing power even though they would be categorised as unbanked is quite high. As presented in this proceeding paper (Khairuddin M. A., et al., 2008), we believe prepaid card would be the best alternative solution for this type of consumers.

Moreover, in that proceeding paper (Khairuddin M. A., et al., 2008), by applying AS/NZS 4360:2004 Risk Management standard as the preferred methodology, it has already highlighted some of the major risks and presented the necessary treatment (from the aspect of regulation and technical) that can be use to minimize or eliminate the affect of the risks or the existence of the threats itself. However, the scope of that proceeding paper is only limited to the perspective of the prepaid card issuers.

Acknowledging the fact that the prepaid cards industry is made up of several entities or stakeholders, it is our intention that for this paper, the analysis and discussion would be on and from the perspective of the consumers.

Therefore this paper will present an analysis on the acceptance and perception of consumers towards prepaid cards especially open-loop cards. Section 2 will discussed the methodologies used in this research. Then, the results and findings on consumer perceptions toward prepaid cards will be presented in Section 3, and the relevant Figures will be represented in the last Section. Finally, this paper will conclude the findings in Section 4. 


\section{Methodology}

Our preferred tools and references would be primarily from the Internet consisting of academic papers, research papers, white papers, news clipping and forums. In addition, we plan to conduct and distribute a simple survey to the consumers.

\section{Results and Findings}

\subsection{Consumers Perceptions on Prepaid Cards}

For us to obtain a basic understanding on the usage and perception of consumers toward prepaid cards, we have created and administered a simple survey using a prepared questionnaire consisting of 3 sections containing 10 questions related to the participants' background, usage pattern and recommendations. Details are as follows,

Title:

\section{"A Survey on the Usage of Prepaid Cards"}

Section A: Customer Background.

Number of questions: 5

Question 1 - Age

Question 2 - Gender

Question 3 - Occupation

Question 4 - Do you have a credit card/ debit card/ prepaid card?

Question 5 - How often do you use your cards?

Section B: Customer Usage Pattern.

Number of questions: 3

Question 6 - What kind of prepaid cards you have used or currently using?

Question 7 - What attracts you to use prepaid cards?

Question 8 - Rate your experience of using prepaid cards

Section C: Customer Recommendation.

Number of questions: 2

Question 9 - What is/ are the action(s) you believe could help improve the usage of prepaid cards?

Question 10 - Due to the current economical crisis, would you prefer to use cards (credit/ debit/prepaid) or cash?

3.2 Result of the Survey

First and foremost, we would like to highlight that this survey has several considerations that include,

- Limitation due to time, cost and nature of studies (coursework) constraint

- This is a basic and simple survey (no reliability and validity controls applied)

- Sampling population only limited to RMIT MC159 full time and part time students

The total numbers of questionnaires distributed are 30 sheets with $90 \%$ response rate $(27$ completed forms returned).

Based from the result of Section A,

- Majority of the participants are over 25 years' old, male and currently full time students.

- $85 \%$ of the participants are active users of card payment scheme (credit card/ debit card / prepaid card), shown in Figure 1.

- $61 \%$ of them utilized their cards frequently (once a week), with $17 \%$ used it in day to day basis.

Based from the result of Section B,

- 77\% of the participants are familiar with (have used and currently using) open-loop prepaid cards

- The features that attract the participants towards prepaid cards (based on its popularity) are ease of use $(38 \%)$, security (15\%), anonymity (11\%), low spending limit (11\%), and no bank account required $(11 \%)$ and others (14\%) such as collectable card design, able to integrate with web payment and can be use as gifts, shown in Figure 2. 
- $52 \%$ of the responses rate prepaid cards customer registration, easiness of usage and merchant acceptance to be good, while $27 \%$ believe it can be improve.

Based from the result of Section C,

- $50 \%$ of the responses believe that by minimizing the fees, this could improve the usage of prepaid cards. Meanwhile, $27 \%$ of the responses believe that more merchants' acceptance is vital in improving it.

- As for the preferences of using cash or cards during this current economical state, $58 \%$ of the participants prefer to use cards as it is convenience, easy to use, easy to control spending and limit, and more secured than cash. Even one of the correspondents wrote that these advantages justify the rate of fees imposed by the card issuers. Please refer to Figure 3.

\subsection{Complaints Gathered from the Internet}

Among the complaints and grievances expressed by prepaid cards customers, as reported on the Internet are,

- Card issuers did not take the proper manner in advising the consumer on the term and conditions of the card usage resulting in denial of services for customers holding prepaid cards with a balance of less than AUD\$10 (Wood A., 2009).

- Value of the gift cards depreciate after the expiration date. In this case, the value of the Wish Gift Card was initially AUD $\$ 100$ but after 12 months would only give the customer AUD\$95 of purchasing power. Moreover, the expiry date was not printed on the card itself (Reid K., 2008).

- Merchants or stores are unable to accept prepaid card transaction due to lack of equipment (Hexactly, 2008).

- The amount of sensitive and private information required from a customer in order to activate the prepaid cards. In this case, the information requested by the issuer (for CANVAS prepaid VISA cards) includes the customer's telephone numbers, full scanned detailed copy of birth certificate and drivers license. Also the number of fees and liability imposed to the customers are basically similar to credit card (one example is that the customer is liable for any negative balance incurred) and not really specific to the nature (prepaid) of the card (Gellato, 2008).

- In the USA, fees imposed on the usage of unemployment debit cards (prepaid) services such as out-of-network ATM withdrawal, customer dial-in helpline and overdraft charges sparks a wave of complaints from the customer saying that it is irresponsible for the issuers (banks) to implement this practice and inconvenience for them (unemployed customers) to be burden by this inappropriate charges. It was also reported that in Missouri alone, the bank's revenue would yield up USD \$6.3 million a year due to the collection of these fees (Leonard C., 2009).

\section{Conclusion}

In conclusion, the outcome from both of the exercise (result of the survey and complaints gathered from the Internet), we can deduce that,

i. Card payment scheme specifically prepaid cards are gradually being accepted and perceived by the general public as a good candidate for cash replacement. The main group of users is basically teenagers, students and unemployed, and this was initially the targeted market by the card issuers. As per the proceeding paper (Khairuddin M. A., et al., 2008), this group can be categorized as the un-banked users. Among the factors that attract the customers are conveniences (easy to use and carry around), security (less vulnerable than cash and other card payment schemes), anonymity and controls (budget control and spending limit).

ii. However, one major factor that could hinder the acceptance of the customer towards the use of prepaid cards is the question of undisclosed and obscured fees imposed by the issuers. These fees include (but are not limited to) ATM service charges, overdraft charges and helpline assistance. Even though the amount of the fees are quite small ( 1 or $2 \%$ of the value of the card) the effects are quite significant and worrying. Furthermore, un-banked customers specifically unemployed who are being given benefit entitlement card (gift cards) argue that it is irresponsible and wrong for the issuers to impose this inappropriate fees (Leonard C., 2009), as it is the issuer's moral obligation and responsibility to put the interest of the customers first rather than business, especially during recession.

Terms and regulations need to be written and presented in a way that is clear and people friendly. It is the responsibility of the issuers to conduct their business in an ethical and moral manner, and what better way to 
adhere to these notions if not by giving full disclosure of their products and services. Nonetheless, customers should always remember to be aware and due diligent when engaging with the market and its offerings.

\section{References}

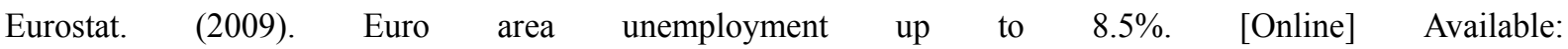
http://europa.eu/rapid/pressReleasesAction.do?reference=STAT/09/45\&type=HTML\&aged=0\&language=EN\& guiLanguage $=\mathrm{en}$

Gellato. (2008). Possible identity theft? Canvas CC. [Online] Available: http://forums.whirlpool.net.au/archive/955185

Greber, J. (2009). Australia Jobless Rate Jumps Most in 18 Years to 5.7\%. [Online] Available: http://www.bloomberg.com/apps/news?pid=newsarchive\&sid=a29jjElS3Ibg

Hexactly. (2008). EB refusal to accept EB Gift Card. [Online] Available: http://forums.whirlpool.net.au/archive/973729

Khairuddin, M. A., et al. (2008). Risk Mitigation Strategies for the Prepaid Card Issuer in Australia. The 6th Australian Information Security Management Conference, Edith Cowan University, Perth Western Australia, pp.101 - 109.

Leonard, C. (2009). Jobless Hit With Bank Fees on Benefits. [Online] Available: http://www.infowars.com/jobless-hit-with-bank-fees-on-benefits/

Mutikani, L. (2009). U.S. sheds fewest jobs in 6 months. [Online] Available: http://www.reuters.com/article/2009/05/08/us-usa-economy-idUSTRE5472SK20090508

Reid, K. (2008). Response to complaint from Woolworths Wish Gift Card.

TradingEconomics.com and U. K. O. f. N. Statistics. (2009). U.K. Jobless Total Hits 2.2 Million. [Online] Available: http://www.tradingeconomics.com/articles/article.aspx?file $=05122009092600 . \mathrm{htm}$

Wood, A. (2009). Gift card scheme raises hackles. [Online] Available: http://www.theleader.com.au/news/local/news/general/gift-card-scheme-raises-hackles/1423300.aspx

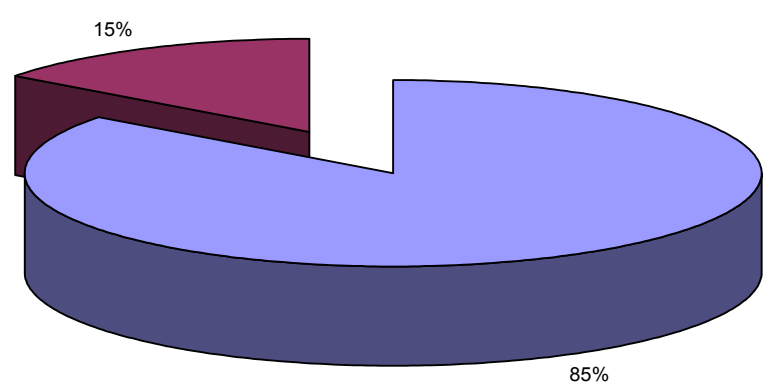


What Attracts You to Use Prepaid Cards?

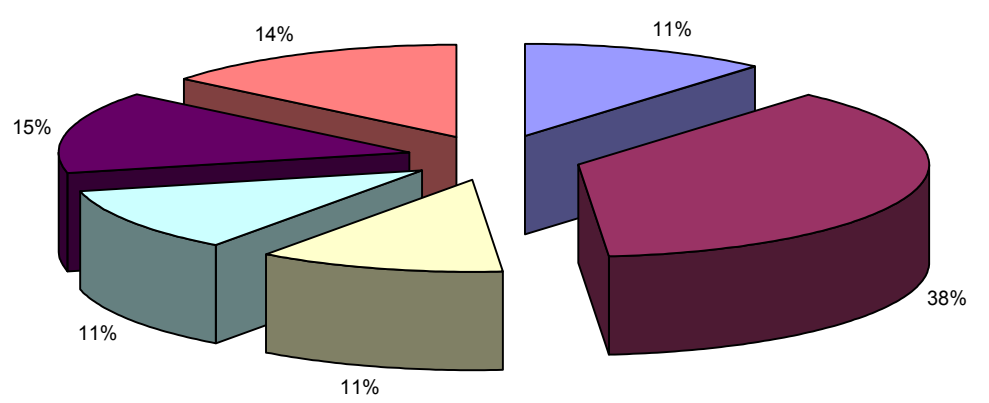

Figure 2. Response to Question 7 (in percentage)

Due to the Current Economical Crisis, Would You Prefer to Use Cards or Cash?

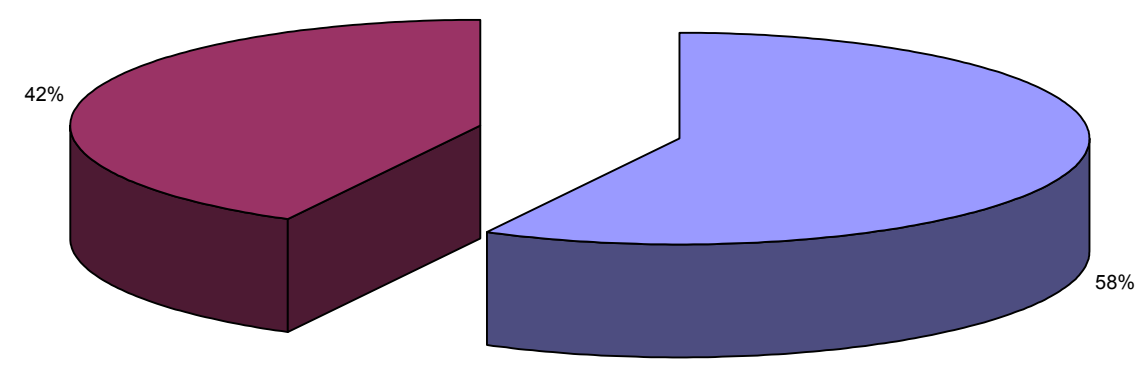

Figure 3. Response to Question 10 (in percentage) 